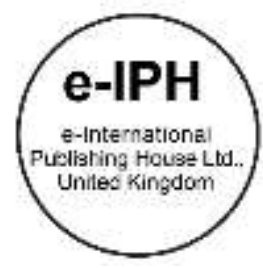

\title{
Users' Perceptions, Experiences and Level of Satisfaction with the Quality of a Courtyard Garden in a Malaysian Public Hospital
}

\author{
Madihah Mat Idris ${ }^{1,3}$, Magda Sibley², Karim Hadjiri \\ ${ }^{1} \mathrm{PhD}$ student, ${ }^{2}$ School of Architecture, Faculty of Social Science, \\ University of Sheffield, Sheffield, United Kingdom \\ 3 Universiti Sains Islam, Malaysia
}

madihah.usim@gmail.com, magda.sibley@sheffield.ac.uk, khadjri@sheffield.ac.uk

\begin{abstract}
During the 1970s, different types of hospital courtyard design (HCG) were implemented in the planning of Malaysian public hospitals. Consequently, various hospitals of different scales and design concepts were built to provide a better healthcare delivery system for local communities. However, the different typologies of HCG designs are yet to be systematically evaluated. Furthermore, designers and hospital managers are not aware of how different types of HCG perform. Face-to-face interview surveys and field measurements were employed in this study to develop an understanding of users' perceptions, experiences and satisfaction levels with the quality of HCG in a Malaysian public hospital.
\end{abstract}

Keywords: Hospital courtyard garden; perceptions; experiences; level of satisfaction.

eISSN: 2398-4287 @ 2018. The Authors. Published for AMER ABRA cE-Bs by e-International Publishing House, Ltd., UK. This is an open access article under the CC BYNC-ND license (http://creativecommons.org/licenses/by-nc-nd/4.0/). Peer-review under responsibility of AMER (Association of Malaysian Environment-Behaviour Researchers), ABRA (Association of Behavioural Researchers on Asians) and cE-Bs (Centre for Environment-Behaviour Studies), Faculty of Architecture, Planning \& Surveying, Universiti Teknologi MARA, Malaysia.

https://doi.org/10.21834/e-bpj.v3i9.1534

\subsection{Introduction}

A good quality hospital design should not only help patients to recover quickly via a good health delivery system, it should also be able to provide a healthy and comfortable environment for the end users. Long waiting times in a hospital can be daunting to most patients and their families waiting for the consultation time at the clinics and appointments to receive medication at the pharmacy. Thus, providing an outdoor space such as a Hospital Courtyard Garden (HCG) is beneficial to both patients and families as it could become a place for social interaction in which they spend their time waiting in a less stressful outdoor environment away from the congested waiting areas inside the hospital. Moreover, the staff could benefit from the courtyard garden as it provides a space outside the hospital where they could escape for a while from the stark and sterile hospital environment and refresh their minds from working long hours in the hospital.

The inclusion of different types of courtyard designs in the planning of hospital buildings can be seen as early as the 1970s (Mat Idris, Sibley and Hadjri, 2018). However, no systematic evaluation specifically focused on hospital courtyard designs have been conducted to date. This paper is part of a PhD thesis on a Post Occupancy Evaluation (POE) of courtyard design in three public hospitals in Malaysia with the aim to investigate how different types of courtyard designs were integrated into the planning of Malaysian public hospitals, and how they are currently used and performing according to their intended users. As part of the ongoing POE study, this paper aims to: (a) develop an understanding of the perception of users regarding the physical and microclimatic conditions of the HCG; (b) examine users' experiences in the HCG; and (c) gauge the level of users' satisfaction with the HCG.

eISSN: 2398-4287 @ 2018. The Authors. Published for AMER ABRA cE-Bs by e-International Publishing House, Ltd., UK. This is an open access article under the CC BYNC-ND license (http://creativecommons.org/licenses/by-nc-nd/4.0/). Peer-review under responsibility of AMER (Association of Malaysian Environment-Behaviour Researchers), ABRA (Association of Behavioural Researchers on Asians) and cE-Bs (Centre for Environment-Behaviour Studies), Faculty of Architecture, Planning \& Surveying, Universiti Teknologi MARA, Malaysia.

https://doi.org/10.21834/e-bpj.v3i9.1534 


\subsection{Literature review}

\subsection{Post Occupancy evaluation}

POE is a systematic and rigorous process of assessment of buildings that are occupied for a period of time (Preiser, 1995). POE serves to develop an understanding of the occupants' behaviours, perceptions, and satisfaction level as lessons that could be learnt to improve the quality of the physical environment of a building to meet the needs of the building users (Nawawi and Khalil, 2008). POE is not limited to an assessment of the indoor environment of the building, it could also be expanded and conducted to evaluate the outdoor environment (e.g. public squares, parks, plazas, rooftop gardens and courtyard gardens) of a particular building or urban setting (Cooper Marcus and Francis, 1998; Davis, 2011; Cooper Marcus and Sachs, 2014). POE involves several systematic techniques and processes that can be employed depending on the scope of the study (Bordass and Leaman, 2005; Hadjri and Crozier, 2009).

Further, POE is important in the planning and development process of government and public buildings in Malaysia to ensure the facilities are well maintained (Nawawi and Khalil, 2008). The Malaysian Ministry of Health (MOH), in collaboration with the Medical and Health Branch of the Public Work Department in Malaysia initiated the POE of a hospital building in 1997. This initiative mainly focused on inpatient and outpatient facilities such as wards, clinics and laboratories (Mastor and Ibrahim, 2010; Mohd Nawawi, 2011). Nevertheless, there is no record of a systematic investigative POE conducted by governmental bodies or scholars specifically on the courtyard gardens of public hospitals which are used by different types of users (i.e. patients, staff and visitors). To this researchers' knowledge, only one POE study conducted in the paediatric wards in eight hospitals in Malaysia to evaluate the physical design and healing environment in the wards was found in the existing literature. Abbas and Ghazali (2012) revealed that the majority of the patients were dissatisfied with the accessibility to the natural environment in the paediatric wards. However, this study did not investigate on users' perceptions and experiences with the physical and microclimatic conditions of the outdoor garden.

\subsection{Evaluation studies on users' feedback on outdoor gardens in healthcare facilities}

Realising the positive effect of nature on well-being has led the $\mathrm{MOH}$ to incorporate the 'healing garden' design concept for a public hospital in Malaysia which is aimed to promote a healthy environment in the hospital (Ibrahim et al., 2015). As mentioned by Almhafdy et al. (2013), different types of a courtyard garden with different design configuration which include enclosed and semi-enclosed courtyard garden were incorporated in most hospitals in Malaysia. However, the quality and success of the HCGs in Malaysia have not been systematically evaluated until today. Most of the literature on POE and the evaluation of users' feedback regarding outdoor gardens in healthcare facilities were carried out in Western countries (Sachs, 1999; Cooper Marcus and Barnes, 1995; Whitehouse et al., 2001; Sherman et al., 2005; Naderi and Shin, 2008; Davis, 2011; Shukor, 2012; Pasha, 2013; Butterfield, 2014). However, none of this previous research focused explicitly on comparative investigative POEs of HCG with different design configurations and concepts. Very few studies were found to have evaluated user feedback on the quality of the outdoor garden in hospitals in Malaysia (Said et al., 2005; Ibrahim and Jer, 2014). Therefore, a POE study on the quality of the courtyard garden in a Malaysian hospital in a tropical climate country is relevant to be conducted to evaluate the existing HCG so that necessary improvement can be made.

\subsection{Evaluation studies on outdoor thermal environments}

Previous studies that evaluated users' feedback in an outdoor garden in healthcare facilities do not consider the perceptions of users on the microclimatic conditions of the site. Such environmental factors (i.e. air temperature, wind flow and humidity) could also influence user perceptions and experiences and their satisfaction level in the HCG. Microclimatic conditions have a significant impact on people's outdoor sensations in which the study found that air temperature and solar radiation among important determinant of comfort in the outdoor environment (Nikolopoulou and Lykoudis, 2006; Ali and Patnaik, 2018). Nikolopoulou and Lykoudis (2006) also highlighted that too much wind flow could increase user discomfort. However, wind flow is desirable when the heat in the outdoor environment increases. Regarding humidity, people are not very good at predicting the humidity levels (Nikolopoulou and Lykoudis, 2006) and often confuse understanding the humidity situation in the outdoor environment (Sharmin and Steemers, 2018). Despite carrying out a simulation study on the effect of design configurations on microclimatic conditions in HCG in Malaysia by Almhafdy et al. (2014, 2015), very few studies have been conducted on courtyard buildings in Malaysia that examined people's perceptions of the thermal outdoor environment (Makaremi et al., 2012; Kubota et al., 2017) (See Table 1). In addressing this gap, this current study intends to examine the perceptions of users on the physical design and its microclimatic conditions as part of the ongoing POE study to establish a comprehensive guideline for effective courtyard garden design which integrates both the environmental and well-being aspects.

Table 1: Findings of previous studies on outdoor thermal environment in a courtyard building in Malaysia

\begin{tabular}{|c|c|c|c|}
\hline Authors & Case studies & $\begin{array}{l}\text { Building } \\
\text { type }\end{array}$ & Findings \\
\hline $\begin{array}{l}\text { Kubota et } \\
\text { al. (2017) }\end{array}$ & $\begin{array}{l}5 \text { types } \\
\text { Enclosed } \\
\text { courtyard }\end{array}$ & Shophouse & $\begin{array}{l}\text { - This study recommended that a closed, cross-ventilated courtyard was preferable to be utilised in a shophouse in } \\
\text { a hot humid climate to obtain optimum indoor thermal comfort and avoid excessive humidity within the courtyard } \\
\text { area. } \\
\text { - This study also suggested that V-shaped roofs should be implemented to increase the inflow of air from the roofs } \\
\text { into the courtyard area during the night time. }\end{array}$ \\
\hline $\begin{array}{l}\text { Makaremi } \\
\text { et al. } \\
\text { (2012) }\end{array}$ & $\begin{array}{l}2 \text { types } \\
\text { Enclosed and } \\
\text { opened } \\
\text { courtyard }\end{array}$ & $\begin{array}{l}\text { Educational } \\
\text { building }\end{array}$ & $\begin{array}{l}\text { - This study suggested that trees and plants in a courtyard reduced the amount direct solar radiation received on } \\
\text { site and improved the microclimatic condition of the courtyard and people' outdoor thermal comfort } \\
\text { - There are no significant differences found between respondents of different gender but there is a significant } \\
\text { difference in the thermal comfort responses of the international and local student due to the cultural difference. }\end{array}$ \\
\hline
\end{tabular}




\subsection{Methodology}

\subsection{Site description}

Hospital $(\mathrm{H} 1)$ is a specialist public hospital which consists of the 10 floor levels with the capacity to accommodate 704 beds. The site plan of the hospital $(\mathrm{H} 1)$ is elongated along a North-South orientation to minimise sunlight penetration from the East and West, which should improve thermal conditions in both outdoor and indoor spaces (Fig. 1 (a)). The area of the HCG is 2,100 sqm and is surrounded with well-matured plants with broad canopies that provide shade to the ground area and shield sunlight penetration into adjacent spaces around the courtyard garden (See Fig.1 (b)). The large enclosed HCG provided light, airy and spacious areas for social interaction by patients, staff and visitors. It is located on level 2 and is accessed via the main hospital street designed around the courtyard periphery with the aim to link public facilities (e.g. cafeteria; prayer room; toilet; and visitor centre) and outpatient facilities as described and illustrated in the previous study by Mat Idris, Sibley and Hadjri (2018).



(a)

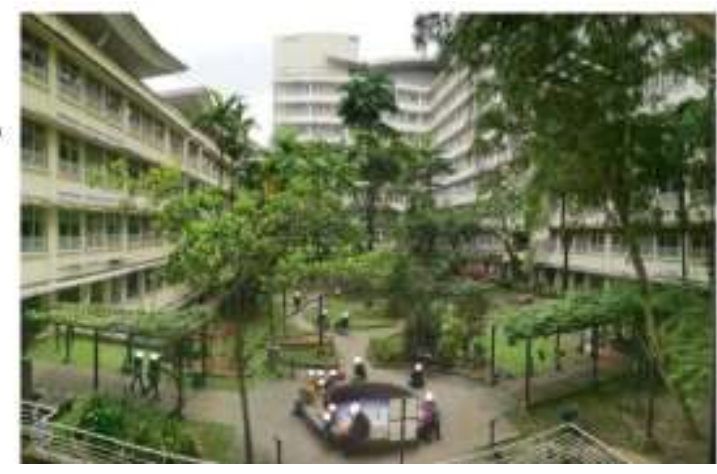

(b)

Fig. 1 (a) Site plan (Source: GDP Architects Sdn. Bhd.); (b) Ariel view of hospital courtyard garden.

\subsection{Ethical approval and data collection}

An ethical approval from the Medical Research Ethics committee (MREC), Ministry of Health Malaysia (MOH), and access permission were obtained from the hospital manager prior to fieldwork commenced. For this study, a face-to-face interview survey and field measurement on the microclimatic conditions were carried out simultaneously in the HCG during two weekdays and two weekends from 9 am to $5 \mathrm{pm}$ each day in March 2018. Prior to the actual fieldwork study, pilot test surveys were carried out, and several improvements were made to the survey questions and instruments to ensure that more accurate responses and robust information gathering could be achieved. Based on the response results received from the pilot study, a face-to-face interview survey method was chosen for this study because a higher response rate from all respondents could be achieved with a reduction in the number of incomplete responses compared to the self-administrated survey method. Moreover, the questionnaire surveys were translated into the local language for proper execution of the survey. During the actual fieldwork, a total of 48 questionnaires were administered to voluntary users sitting on benches in the courtyard garden of the hospital $(\mathrm{H} 1)$. Out of 48 surveys distributed, only 46 surveys with a completed response from the respondents were analysed for this study. The respondents were recruited from the convenient sample chosen over a random sampling of courtyard users $(100 \% ; N=46)$ involving $(13 \% ; n=6)$ patients, $(11 \% ; n=5)$ staff and $(76 \% ; n=35)$ visitors. The numbers of respondents for the patient and staff is slightly lower than visitors because the visitors are the main users of the HCG as reported in the previous study (Mat Idris, Sibley and Hadjri, 2018). A detailed distribution of the demographic data is shown in Table 2.

Table 2: Percentage of distribution of demographic data $(\mathrm{N}=46)$

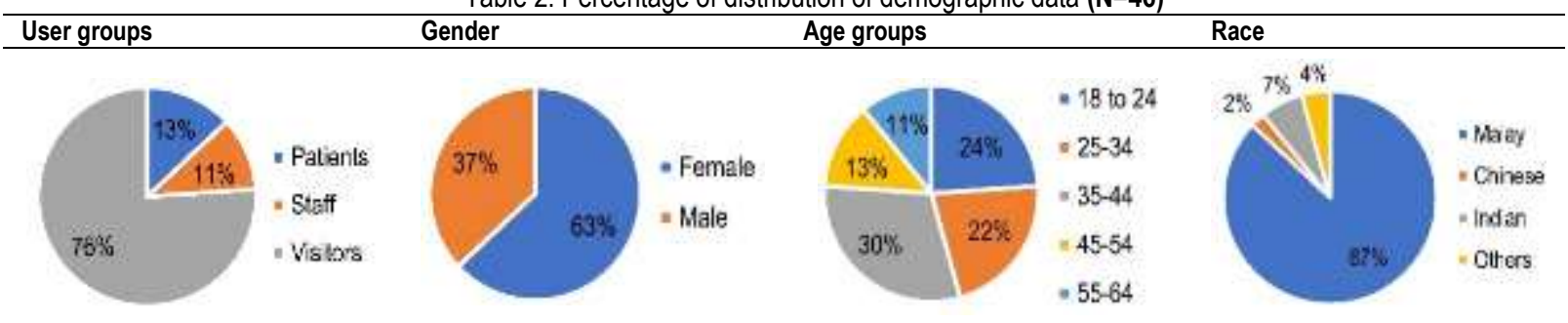

The environmental data of the HCG including air temperature $\left({ }^{\circ} \mathrm{C}\right)$, air relative humidity $(\%)$ and wind flow $(\mathrm{m} / \mathrm{s})$ were measured using an AERCUS 3083 weather station fixed on a tripod at the height of 1.1 metres and placed at the centre of the courtyard garden. A portable environmental metre was also used to record the actual air temperature $\left({ }^{\circ} \mathrm{C}\right)$ and air relative humidity $(\%)$ before conducting face to face interview survey with the courtyard users. In addition, HOBO UA-002-64 was also used to compare the air temperature in the HCG and outside the hospital. 


\subsection{Limitations of the study}

Several limitations were noticed regarding the sampling procedures adopted in this present study. First, the sample of respondents was limited to a small number $(\mathrm{N}=46)$ respondents for the examined case study: Hospital $(\mathrm{H} 1)$. Based on the observation study by Mat Idris, Sibley and Hadjri (2018), visitors were the main users. However, not all visitors were willing to participate in the interview surveys because some of visitors were worried about their family members, relatives and friends who had been admitted to the hospital because of a medical emergency. Only those who were sitting and spent time in the HCG were approached to participate in the interview surveys. Very few patients and staff were approached to participate in the interview surveys because these groups were the type of users who least visited and spent time in the HCG of the hospital (H1) (Mat Idris, Sibley and Hadjri, 2018). Furthermore, the researcher only approached stationary users who were sitting on shaded benches in the garden, and those who were passing through the courtyard garden were not interviewed. For a future study, larger sample sizes will add more robust information for the understanding of the perceptions of each type of users' groups (i.e. patients, staff and visitors). Nevertheless, this is dependent on the availability of courtyard users within the context of the case study hospitals because not every hospital courtyard garden in Malaysian public hospitals will have a large sample of respondents (i.e. courtyard users) during the field survey days. Based on the observation on users' activities in the HCGs, some of the HCG in Malaysian public hospitals were found to be underused and non-used at all because they were locked, located in secluded areas or had access restrictions. Moreover, the survey and field measurements were not carried out during the rainy period. In addition, people's thermal sensations in sunny areas were not discussed here. This was because most of the respondents avoided sitting in sunny areas as most of them sat in the shaded areas in the HCG.

\subsection{Content of the questionnaire survey and data analysis}

The interview survey was developed based on previous similar studies that focused on the evaluation of outdoor gardens in healthcare facilities and involving different types of users in multiple case studies (Cooper Marcus and Barnes, 1995 ; Whitehouse et al., 2001; Shukor, 2015), was adapted and restructured by adding questions on the comfort perception of outdoor thermal sensations (e.g. air temperature; air movement; and air humidity) such as Sharmin, Steemers and Matzarakis, $(2015$, p.743) and Nikolopoulou and Lykoudis (2006, p.1457). For this study, 7-point ASHRAE scale, 3-point Mcintyre scale and 5-point Likert-type format and were used to obtain information regarding (i) Users' perception on the courtyard setting (Question 8 -13); (ii) Users' experiences in the HCG (Question 20); (iii) Level of user' satisfaction with the provided facilities of the HCG (Question 21-22) (See Table 3). Survey data based on the Likert scale question and multiple-choice questions were coded and analysed using SPSS analysis for a descriptive statistical analysis. The opened ended questions were coded and analysed using Excel for content analysis.

The interview surveys comprised four sections with 23 questions. Only some part of the questionnaire results are presented in this paper and consist of the demographic characteristics of the respondents (Question 1-7), their perceptions (Question 8 -13), experiences (Question 20), level of satisfaction with the HCG (Question 21-22) as well as users' suggestions for improvement (Question 23) (see Table 3).

Further, interview survey questions which asked about user preferences of the HCG (i.e. What do you like (Question 6) and What you do not like about the HCG (Question 7) (open-ended questions)) were not discussed in this paper. In addition, the interview survey questions which asked the respondents to select the image of the courtyard garden which they preferred the most and provide the reason of their selections (Question 14 and 15) were not discussed in this paper. The interview survey with the courtyard users also included: (i) frequency of visitation (Question 16); (ii) the activities they did in the courtyard garden (Question 17); (iii) time spent in the courtyard garden (Question 18); and (iv) reason for visitation (Question 19). The results that focus on the activities and frequency of visitations will be correlated with the results gathered from the behavioural observation to validate the data and provide more robust evidence regarding users' activities that were not discussed in this paper.

Table 3: Part of the questionnaire survey content

\begin{tabular}{|c|c|c|}
\hline (i) PERCEPTIONS & Users' perception of the physical design and microclimatic conditions of HCG & Type of Question \\
\hline \multirow{3}{*}{$\begin{array}{l}\text { Perception on } \\
\text { microclimatic conditions }\end{array}$} & $\begin{array}{l}\text { Question 8: How do you feel with the environment (air temperature) around you at this moment? } \\
\text { (e.g. cold (-3); cool }(-2) \text {; slightly cool }(-1) \text {; neutral }(0) \text {; slightly warm (+1); warm }(+2) \text {; } \\
\text { hot }(+3)) \text {. }\end{array}$ & $\begin{array}{l}\text { - 7-point ASHRAE } \\
\text { scale }\end{array}$ \\
\hline & $\begin{array}{l}\text { - Question 9: Based on your answer in Q. no.8, how would you prefer to be? } \\
\text { (e.g. cooler; no changes; warmer). }\end{array}$ & $\begin{array}{l}\text { - 3-point Mclntyre } \\
\text { scale }\end{array}$ \\
\hline & $\begin{array}{l}\text { - Question 10: How do you feel of the wind at this moment? } \\
\text { (e.g. stale; little wind; OK (feel comfortable); windy; too much wind). } \\
\text { - Question 11: Question 11: How do you feel of the humidity at this moment? (e.g. very damp; damp; } \\
\text { OK (feel comfortable); dry; very dry). }\end{array}$ & $\begin{array}{l}\text { - 5-point Likert scale } \\
\text { questions }\end{array}$ \\
\hline $\begin{array}{l}\text { Perception on } \\
\text { Physical design }\end{array}$ & $\begin{array}{l}\text { - Question 12: From scale } 1 \text { (Not important) to } 5 \text { (Very Important), please rate the environmental design } \\
\text { of courtyard garden that you think are important. (e.g. water fountain; green plants; flowering shrubs; } \\
\text { sitting area; walkway and green grass). } \\
\text { - Question 13: From scale } 1 \text { (Not important) to } 5 \text { (Very Important), please rate the environmental design } \\
\text { of courtyard garden that you think are important. (e.g. a shaded area; a daylighting in the courtyard } \\
\text { area; a daylighting into the adjacent space; a breeze and fresh air; and comfortable air temperature in } \\
\text { the hospital courtyard garden). }\end{array}$ & $\begin{array}{l}\text { - 5-point Likert scale } \\
\text { questions }\end{array}$ \\
\hline (ii) EXPERIENCES & Users' experience in the HCG & Type of Question \\
\hline Changes in mood & $\begin{array}{l}\text { - Question 20: On a scale of } 1 \text { (Strongly Disagree) to } 5 \text { (Strongly Agree), please rate how you feel when } \\
\text { come and walk around in this courtyard garden. } \\
\text { (e.g. I feel more relaxed and less stressed; I feel more refreshed and rejuvenated; I feel pleased, } \\
\text { positive and better; I feel calmer and able to think positively; I feel more connected into religious and }\end{array}$ & $\begin{array}{l}\text { - 5-point Likert scale } \\
\text { questions }\end{array}$ \\
\hline
\end{tabular}




\begin{tabular}{|c|c|c|}
\hline & $\begin{array}{l}\text { spiritual way; I feel comfortable when sitting or walk around this courtyard garden; I feel safe when } \\
\text { sitting or walk around this courtyard garden; I don't feel any difference in mood) }\end{array}$ & \\
\hline iii) SATISFACTION & Users' satisfaction on the environmental design quality of HCG & Type of Question \\
\hline $\begin{array}{l}\text { Environmental design } \\
\text { The overall level } \\
\text { of satisfaction }\end{array}$ & $\begin{array}{l}\text { - Question 21: On a scale from } 1 \text { (Very dissatisfied) to } 5 \text { (Very satisfied), please rate which design } \\
\text { aspects of the courtyard garden in this building is satisfying to you. } \\
\text { (e.g. Accessibility to the courtyard from the entrance, accessibility for disable and wheelchair users, } \\
\text { visibility of the courtyard garden from the adjacent space, the location of the courtyard, the layout and } \\
\text { planning, the way finding to the courtyard (i.e. signage), the colour of the adjacent wall, the landscape } \\
\text { elements). } \\
\text { - Question 22: How would you rate the overall quality of Hospital (H1) courtyard garden? } \\
\text { - (e.g. poor; fair; good; very good; and excellent). }\end{array}$ & $\begin{array}{l}\text { - 5-point Likert scale } \\
\text { questions }\end{array}$ \\
\hline iv) SUGGESTION & Users' suggestion for improvement of HSG & Type of Question \\
\hline Suggestion for changes & $\begin{array}{l}\text { - Question 23: Is there anything that you would like to see changed or added in this courtyard } \\
\text { garden? }\end{array}$ & $\begin{array}{l}\text { - Open-ended } \\
\text { questions }\end{array}$ \\
\hline
\end{tabular}

\subsection{Findings and discussion}

\subsection{Users' perception of the physical design and microclimatic conditions}

For the purpose of understanding users' perception on the physical conditions within the HCG, several questions such as the perceptions on the landscape elements, environmental design and microclimatic conditions were asked among the courtyard users of HCG.

\subsubsection{Perception on the physical design in the HCG}

Throughout the detailed survey ( $\mathrm{N}=46$ respondents), the majority of courtyard users reported that all landscape elements (e.g. the water fountain, green plants, sitting areas, flowering plants, pedestrian walkways and green grass) were important elements in the HCG. This contrasts with a previous study in California which reported that the sound of running water was the most preferred landscape element among garden users (Whitehouse et al., 2001). Surprisingly, in a Malaysian context, according to the frequencies of responses obtained here, flowering plants are 'very important' to the courtyard users ( $69.6 \%, \mathrm{n}=32$, of total respondents). Few respondents thought that the water fountain was less important to them $(13 \%, n=6)$ and not important $(4.3 \%, n=2)$ (See Fig. 2). Based on the interview survey, child safety was the main reason why the respondents (i.e. visitors) felt that it was less important to be included in the HCG as they worried that their child might fall into the water fountain. Another reason was that the water features (if improperly maintained) could attract mosquitoes which are harmful to the hospital environment and its occupants. Nevertheless, more than half of the respondents stated that water features are important to them and some of the interviewed respondents mentioned that it was important to provide water features in the garden because it could provide them a calm feeling while listening to the sound of running water where they could relieve their stress from the congested waiting area inside the hospital. However, the water features in this hospital were not turned on during the period of fieldwork study at Hospital (H1).

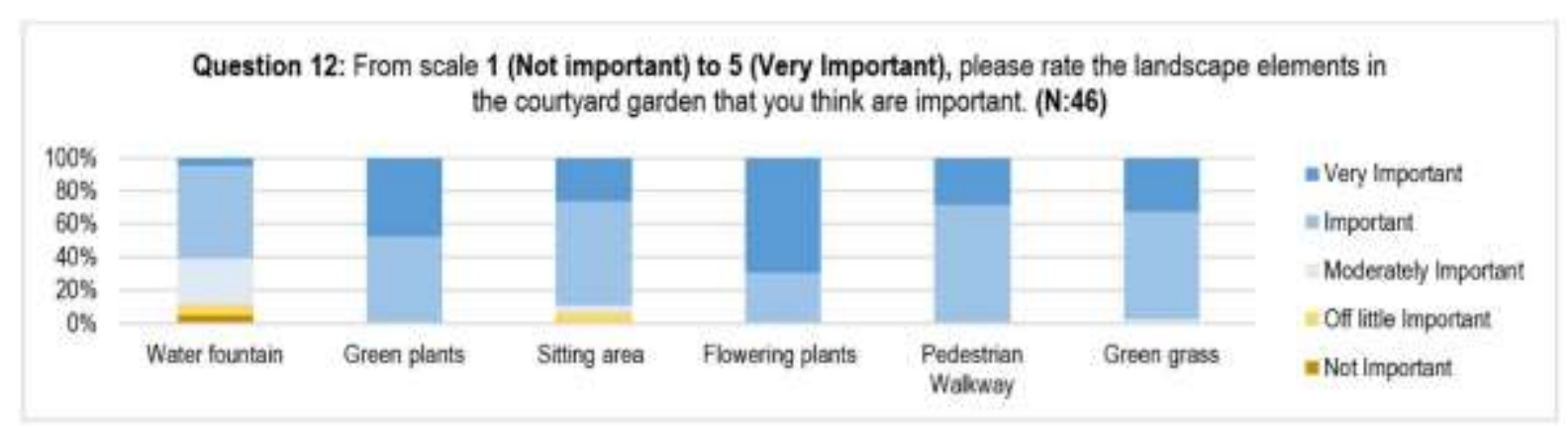

Fig. 2. Users' perception of the landscape elements in HCG

Further, the survey on the HCG environmental design aspects revealed that out of 46 respondents, the majority perceived shaded areas, daylighting in the courtyard area, daylighting into the adjacent space, breeze and fresh air and comfortable air temperature as 'important' (+1) for them (See Fig. 3). According to the survey results, the majority of the respondents $(82.6 \%, n=38)$ responded that the shaded area was 'important' (+1) for them. Cooper Marcus and Barnes (1995) highlighted that several design factors such as poor vegetation, shading and seating influenced the utilisation of the outdoor garden in hospitals. Moreover, Makaremi et al. (2012) and Pasha and Shepley (2013) also mentioned that one of the reasons for reduced garden visitation and lower duration of time spent in the outdoor garden was because of dissatisfaction with the seat option and shade. Based on the previous observation study conducted by Mat Idris, Sibley and Hadji (2018), this HCG at (H1) hospital offered a variety of seating options, all well-shaded by the building as well as the big canopy trees, thus creating a comfortable place for people to spend longer time in the HCG. Another important element of the HCG which received a higher vote for 'important' $(+1)$ with $78.3 \%,(n=36)$ is air temperature. In addition, more than half of the respondents responded that breeze and fresh air are important elements for the HCG. Only one respondent (i.e. inpatient) $(2.2 \%, n=1)$ stated that breeze and fresh air were 'not important' (-2) to her because she preferred a warmer environment in the HCG to escape the air conditioning area in the ward. To add, this respondent also felt uncomfortable with the breeze that flowed in the courtyard as she 
preferred a less windy environment. This survey also reported that several respondents stated that the daylighting into the adjacent space is 'not important' $(2.2 \%, n=1)$ and 'off little important' $(13.0 \%, n=6)$.

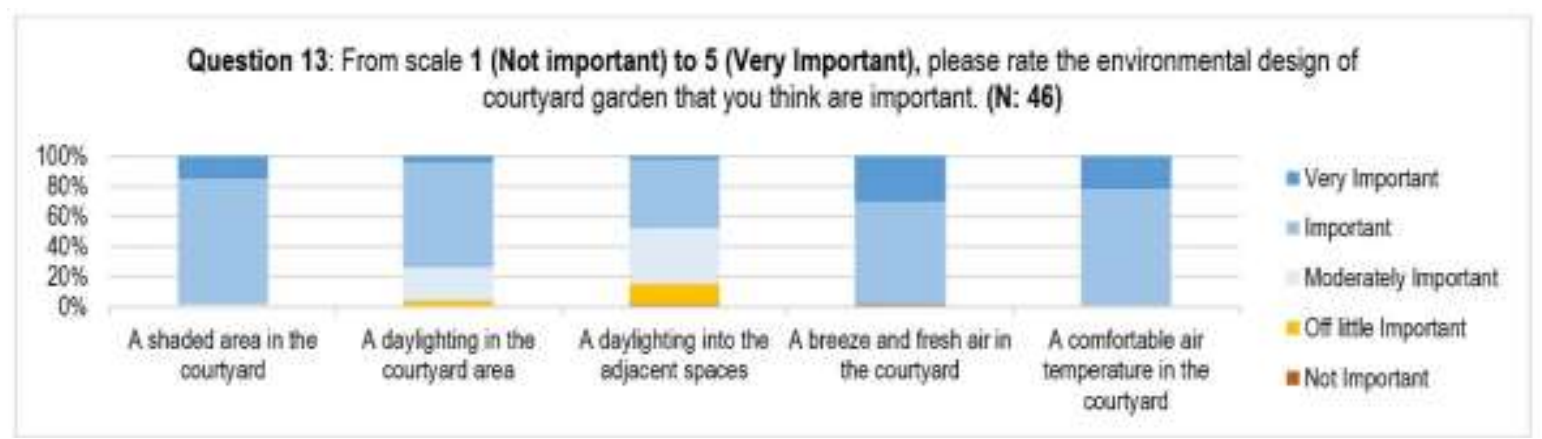

Fig. 3. Graph percentage of users' perception of the environmental design of the HCG

\subsubsection{Perception on the microclimatic conditions of HCG}

Malaysia is located in a tropical climate region as having a considerable high density of solar radiation, high daily air temperature, high humidity, excessive rainfall and little wind flow (Makaremi et al., 2012; Malaysian Meteorological Department, 2012). Outdoor thermal comfort could be affected by various environmental factors including air temperature, wind flow and air humidity (Ahmed, 2003; Sharmin, Steemers and Matzarakis, 2015). In addition, other parameter such as cultural, personal and psychological factors also affected people's thermal sensation (Nikolopoulou and Lykoudis, 2006; Sharmin and Steemers, 2018).

\section{i) Field measurement on the microclimatic conditions of the HCG}

In this study, microclimatic parameters such as air temperature $\left({ }^{\circ} \mathrm{C}\right)$, wind flow $(\mathrm{m} / \mathrm{s})$ and air humidity $(\%)$ were measured on site using AERCUS 3083 weather station during the field survey from 9 am to $5 \mathrm{pm}$ each day to understand people's thermal sensations in the HCG. The average temperature recorded throughout the field survey was $29.4^{\circ} \mathrm{C}$ while relative humidity was $69.1 \%$. Based on the Beaufort scale, the average wind speed was $1.3 \mathrm{~m} / \mathrm{s}$ which is light air (at a height of 1.1 metres) (see Table 4).

Table 4: Data of microclimatic conditions in the HCG during survey days

\begin{tabular}{lllll}
\hline \multicolumn{4}{l}{ Summary of the microclimatic conditions during survey days between } & 9.00am to 5.00pm - 4 days (interval: 15 min) \\
\hline Environmental data & Max & Min & Mean & SD \\
\hline Air temperature, $\left({ }^{\circ} \mathrm{C}\right)$ & 32.7 & 26.3 & $\mathbf{2 9 . 4}$ & 1.2 \\
\hline Relative humidity, $(\%)$ & 90 & 50 & 69 & 6.85 \\
\hline Wind speed, $(\mathrm{m} / \mathrm{s})$ & 3.19 & 0.31 & $\mathbf{1 . 3}$ & 0.81 \\
(Beaufort scale) & Light breeze & Light air & Light air & Light air \\
\hline
\end{tabular}

In addition, the air temperature in the courtyard garden and outside the hospital was recorded with HOBO UA-002-64 from 9 am to $5 \mathrm{pm}$ on 10 March 2018. The results showed that the overall air temperature in the courtyard garden was slightly lower than that recorded outside the hospital building with average temperature difference of $2.0^{\circ} \mathrm{C}$. The temperature recorded at $1 \mathrm{pm}$ revealed that the air temperature was $27.3^{\circ} \mathrm{C}$ in the $\mathrm{HCG}$ and $31.4^{\circ} \mathrm{C}$ outside the hospital with a temperature difference of $4.1^{\circ} \mathrm{C}$ (see Table 5). This clearly indicates that the HCG created a cooler microclimate which produced a comfortable environment for people to sit and spend time in the courtyard garden.

Table 5: Environmental data of the air temperature in the HCG and outside the HCG

\begin{tabular}{llll}
\hline \multicolumn{4}{l}{ Difference of the air temperature recorded between outside HCG and inside HCG (10.3.2018) } \\
\hline Time & Outside HCG & In the HCG & Temperature difference \\
\hline $\mathbf{9} \mathbf{~ a m}$ & 25.7 & 25.4 & 0.3 \\
\hline $\mathbf{1 1} \mathbf{~ a m}$ & 29.6 & 26.5 & 3.1 \\
\hline $\mathbf{1 ~ p m}$ & 31.4 & 27.3 & 4.1 \\
\hline $\mathbf{3 ~} \mathbf{~ m m}$ & 32.7 & 31.7 & 1.0 \\
\hline $\mathbf{5 ~ p m}$ & 29.5 & 26.9 & 2.6 \\
\hline
\end{tabular}

\section{ii) Users' thermal sensation and preference of air temperature}

Respondents' thermal sensation was measured on an ASHRAE 7-point scale: cold (-3), cool (-2), slightly cool (-1), neutral (0), slightly warm $(+1)$, warm $(+2)$ and hot $(+3)$ to understand courtyard users' perceptions of the air temperature in the HCG. The neutral temperature, a term first introduced by Humpreys (1975), is another useful way to examine thermal sensation (Nikoloupoulou and Lykoudis, 2006). Participants voted for neutral ' $O$ ' to indicate that they neither felt warm or cold (ibid). According to the survey results here, more than half of the respondent $(54.4 \%, n=14$ male, $n=11$ female) voted for 'neutral' $(0)$. This indicated that they felt thermally comfortable within the outdoor neutral temperature which range between $26.2^{\circ} \mathrm{C}$ and $32.7^{\circ} \mathrm{C}$ with an average neutral temperature of $29.2^{\circ} \mathrm{C}$ (see Figure 4 (a) and (b)). In a study conducted in a semi-outdoor area in a food centre building in Singapore located within a tropical climate, Song (2006) revealed that the acceptable temperature range was between $23.0^{\circ} \mathrm{C}$ and $31.2^{\circ} \mathrm{C}$; the neutral temperature 
was $27.2^{\circ} \mathrm{C}$ (Yang, Wong and Jusuf, 2013). The result of this study also confirms those of a previous study conducted by Ahmed (2008), in a tropical climate country, which found that people who wore summer clothing and engaged in outdoor sedentary activities were thermally comfortable in temperatures below $34^{\circ} \mathrm{C}$ with an average air temperature range between $28.5^{\circ} \mathrm{C}$ and $32^{\circ} \mathrm{C}$.

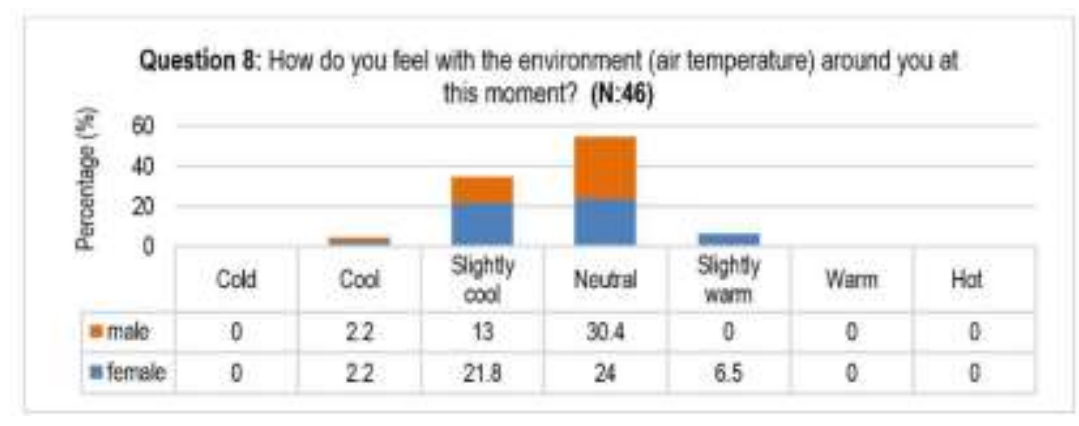

(a)



(b)

Fig. 4. (a) Air temperature thermal sensation votes (ASHRAE 7 point scale); (b) Variation of thermal sensation votes (TSV), in relation to actual air temperature

This present study found that about one third of the respondents ( $34.8 \%, n=10$ female, $n=6$ male) voted for 'slightly cool'. Surprisingly, two respondents perceived the courtyard temperature as 'cool' ( $4.3 \%, \mathrm{n}=1$ female; $\mathrm{n}=1$ male). The survey results indicated that $6.5 \%$ $(n=3)$ voted for 'slightly warm' which female respondents and none of the respondents vote for 'warm' and 'hot' (See Fig. 4 (a)). Some of the respondents likely expressed their thermal sensation in slightly extreme from other respondents' due to different personal factors such as age, different type of clothing, and metabolism rate. This current study found that there was no difference in acceptable thermal sensation between respondents of different gender as revealed in the previous study by Spagnolo and de Dear (2003), Makaremi et al. (2012) and Kruger and Drach (2017). Based on Figure 4 (a), one of the respondents who voted 'slightly warm' (1) was a cancer patient who wore hospital clothing and was placed in the 55 to 64 -year old age group. The previous finding, conducted in Brazil, found that age difference was significant and had an impact on people's thermal sensation as it found that the elderly (over 55-years old) were more vulnerable to higher outdoor temperatures (Pantavou et al. 2013).

Responses to further questions regarding users' preferences of changes to outdoor thermal environment in the HCG based on threepoint scale (i.e. prefer warmer (-1), prefer no change (0), prefer cooler (1) (Mclntyre,1980), revealed that the majority of the respondents preferred 'no changes' $(0)$. This indicated that they were comfortable with the thermal environment that they experienced on site with a total vote of $(71.1 \%, n=20$ female, $n=13$ male) (See Fig. 5 (a) and 5 (b)). It is also interesting to notice that only $26.1 \%$ of the respondents ( $n=9$ female and $n=3$ male) preferred a 'warmer' ( -1$)$ air temperature while $(2.2 \%, n=1$ male) preferred a 'cooler' ( +1$)$ air temperature.

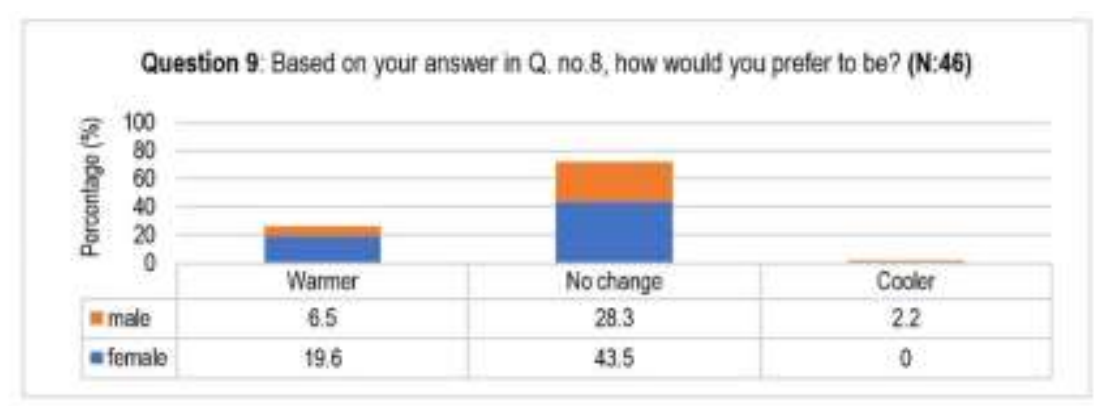

(a)

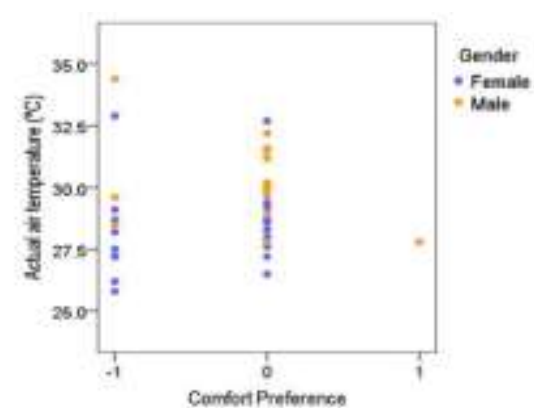

(b)

Fig. 5. (a) Thermal preferences votes (3-point McIntyre scale); (b) Air temperature and thermal preferences votes

\section{iii) Users' sensation on the wind flow and air humidity}

All respondents $(\mathrm{N}=46)$ who were spending time in the HCG were asked about their perception of wind flow and air humidity in the hospital courtyard. The wind sensation ranged from stale $(-2)$ to too much wind $(+2)$. Within the wind flow range of $0.31 \mathrm{~m} / \mathrm{s}$ (light air) to $3.19 \mathrm{~m} / \mathrm{s}$ (light breeze), $28.3 \%$ ( $n=13$ (8 female and 5 male)) of the respondents voted 'OK' $(0)$ in which they felt comfortable with the wind flow at the site. $30.5 \%$ ( $\mathrm{n}=14$ (9 female and 5 male) of the respondents indicated their wind sensation as 'windy' $(+1)$ and 'too much wind' (+2). Less than half of the respondents $(41.2 \%, n=19)$ felt 'little wind' $(-1)$ and 'stale' $(-2)$ (See Fig. $6(a))$. Interestingly, the findings here showed that the majority of respondents who spent time sitting in the HCG felt the wind in the enclosed HCG. The light air speed in the HCG recorded during the day of the field surveys range between $0.31 \mathrm{~m} / \mathrm{s}$ and $1.3 \mathrm{~m} / \mathrm{s}$ enhancing heat transfer between the air and the human body, thus increasing the cooling process of the human body. As a result, $93 \%$ of the respondents reported that they felt comfortable even though the air temperature is high because of the presence of a light breeze in the HCG. This study inferred that the design of the roof in Curve V-shape also bring the wind flow into the courtyard garden as suggested in the previous study of a shophouse in Malaysia (Kubota et al., 2017). Moreover, large canopy trees and vegetations in the courtyard garden enhance the microclimate in the courtyard as it provides shade that reduces the amount of solar radiation and provides a comfortable environment 
(De Abreu-Harbich, Labaki and Matzarakis, 2015; Ghaffarianhoseini, Berardi and Ghaffarianhoseini, 2015) which encourage more users to spent time sitting in the HCG (Mat Idris, Sibley and Hadjri, 2018).

Regarding the humidity sensation votes, a majority of the respondents $(65.2 \%, n=30$ (21 female and 9 male)) felt 'OK' (0) in which they felt comfortable with the air humidity in the HCG ranges of $60.5 \%-85 \%$ during the survey days $(9 \mathrm{am}-5 \mathrm{pm})$. $15.2 \%$ of the respondents ( $n=4$ female; 3 male) considered the air humidity as 'Dry' $(+1)$ and 'Very Dry' $(+2)$, whereas $19.6 \%$ of the respondents $(n=4$ female; 5 male) voted for 'Damp' (-1) and 'Very Damp' (-2) (See Fig. 6 (b)).

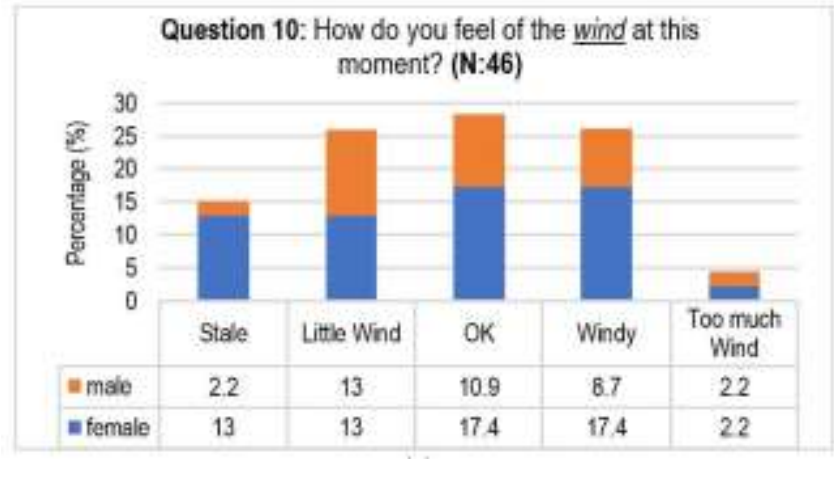

(a)

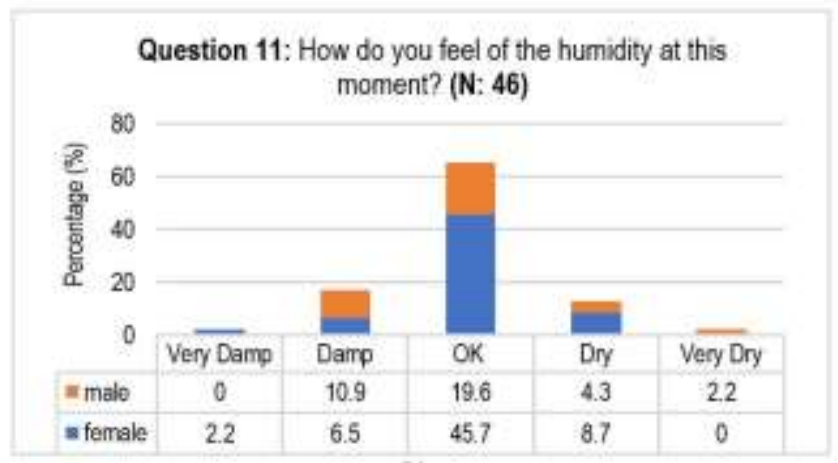

(b)

Fig. 6. (a) Wind sensation votes; (b) Humidity sensation votes

\subsection{Users' experiences in the hospital courtyard garden}

In addition to their perception of the physical and microclimatic conditions of the HCG, respondents were also asked about their feelings while spending time in the HCG. They were asked to rate their feelings on a 5-point Likert scale. Questions ranged from 'Strongly Disagree' (-2) to 'Strongly agree' (+2). (See Fig.7). The survey results indicated that the majority of respondents reported positive changes to their mood while being in the HCG. The vast majority of the respondents 'agree' $(+1)$ that they felt more relaxed and less stressed $(93.5 \%, n=43)$, more refreshed and rejuvenated $(87.0 \%, n=40)$, feel pleased, positive and better $(84.8 \%, n=39)$, feel calmer and able to think positively $(84.8 \%, n=39)$, comfortable $(84.8 \%, n=39)$, and safe $(82.6 \%, n=38)$. Furthermore, more than half of the respondents $(58.7 \%, n=27)$ 'agree' $(+1)$ that being in the HCG made them feel more connected to their religious or spiritual self. In contrast, only a very few disagreed $(4.3 \%, n=2)$. This finding supports the previous study that the human interaction with the natural environment (i.e. plants, flower, sound of water, fresh air, natural lighting) have a positive effect on moods of those who visit and view the garden (Cooper Marcus and Barnes, 1995; Whitehouse et al., 2001; Sherman et al., 2008; Shukor, 2015)

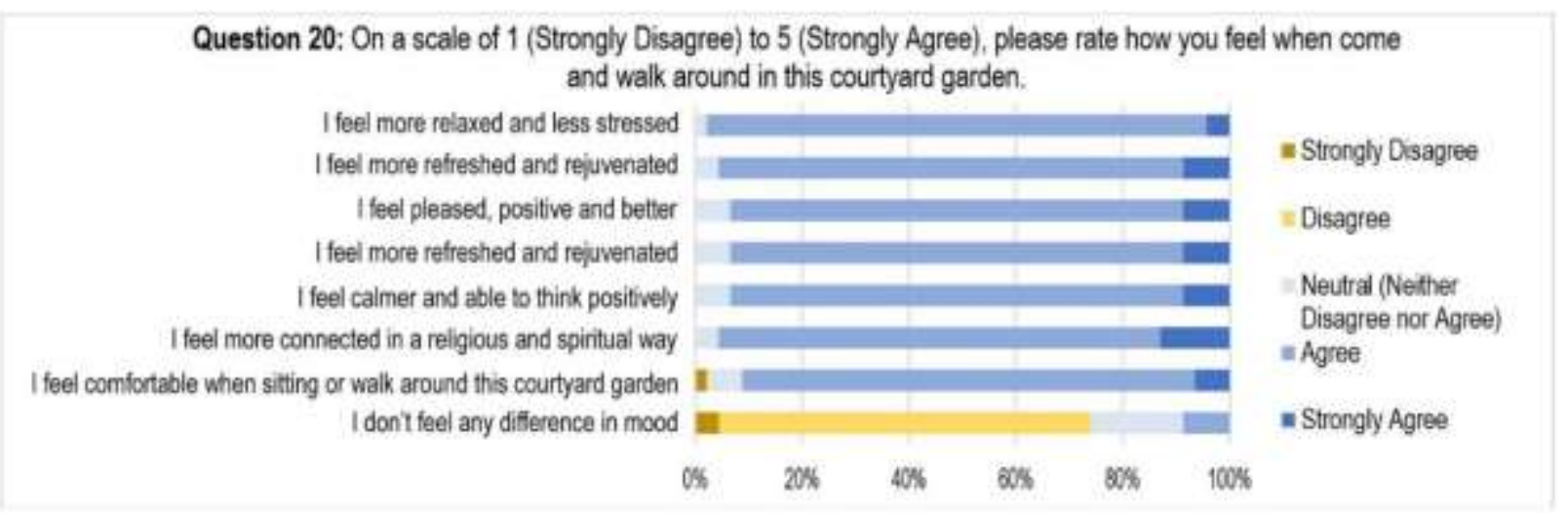

Fig. 7. Users' experiences in the Hospital Courtyard Garden

\subsection{Level of satisfaction with the design quality of the hospital courtyard garden}

\subsubsection{Level of satisfaction with the environmental design of HCG and overall quality of HCG}

More than $80 \%$ of the respondents expressed their satisfaction with all physical characteristics of the HCG (i.e. accessibility, visibility, wayfinding, design and planning) when asked to vote from slightly satisfied (0), satisfied (+1) to very satisfied (+2) (See Fig. 8). All respondents $(100 \%, n=46)$ expressed being satisfied with the location of the courtyard near the cafeteria and more than $80 \%$ of the respondents expressed satisfaction with its accessibility and visibility (i.e. accessibility for wheelchair users (86.9\%, $n=40)$, accessibility from main lobby to courtyard area $(82.6 \%, n=38)$, accessibility to different departments $(95.7 \%, n=44)$, entrances of courtyard garden $(91.3 \%, n=42)$, visibility of the courtyard garden from the adjacent space $(95.7 \%, n=44)$ and wayfinding to the courtyard garden $(93.5 \%$, $n=43)$. Very few respondents expressed dissatisfaction with the layout and planning of the HCG $(17.4 \%, n=8)$, accessibility from the main lobby to the courtyard garden $(17.4 \%, n=8)$ and accessibility of the courtyard for wheelchair users $(13.1 \%, n=6)$. Nevertheless, 
nearly half of the respondents $(47.8 \%, \mathrm{n}=22)$ expressed their dissatisfaction with the landscape elements (i.e. water fountain, types of herbs garden, seating). In addition, $41.3 \%(n=19)$ were dissatisfied with the colour of the wall around the HCG which slowly began to fade.



Fig. 8. Level of satisfaction with the environmental design of hospital courtyard garden

\subsubsection{Satisfaction level with the overall quality of HCG}

More than half of the respondents $(67.4 \%, n=31)$ reported that they were satisfied with the overall quality of the $(H 1) H C G$. For example, $41.3 \%(n=19)$ of the respondents rated it as 'Good' $(0), 23.9 \%(n=11)$ rated it as 'very good' $(+1)$ and $2.2 \%(n=1)$ rated it as 'Excellent' (+2). Only a few respondents $(8.7 \%, n=4)$ rated the quality of the HCG as 'Poor' and $(23.9 \%, n=11)$ rated it as 'Fair' ( -1$)$. (See Fig. 9).

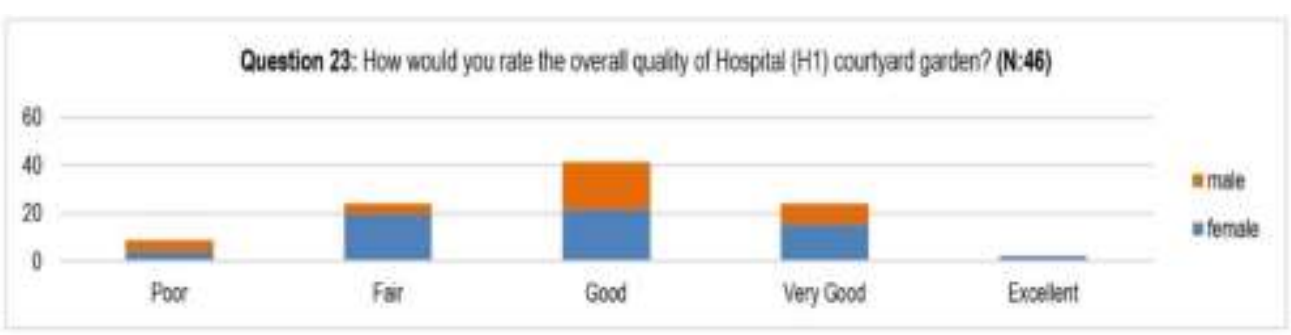

Fig. 9. Rating scale on the overall quality of hospital courtyard garden

\subsubsection{Users' suggestion for improving the quality of the HCG}

Despite the benefits and potentials that this HCG has evidenced, there are several things the hospital manager and the Ministry of Health should take into consideration to improve and maintain the existing facilities in HCGs. Based on the open-ended survey, $93 \%$ $(n=43)$ of the respondents requested some changes and provided suggestions for improvement of the HCG. More than half of the respondents $(52.1 \%, n=24)$ requested adding more seating $(56.5 \%, n=26)$ and better maintenance. Maintenance here included fixing the water fountain, improving labelling of the plants, enhancing the cleanliness of the HCG, removing fallen leaves and replacing broken seating. Regarding the existing water fountain, some parents reported concerns over the safety of their child due to the possibility of falling into the water feature pond. These can be easily addressed by the hospital management through the installation of a safety net or wire mesh. Another suggestion made by some respondents was to have more plants in the HCG and improve existing plants labelling so that the landscape can provide educational role for both children and adult users. The $\mathrm{H} 1$ hospital has the potential to be a good example of a HCG in a tropical climate provided that possible measures and care regarding the existing facilities are taken into consideration.

\subsection{Conclusion and recommendations}

This study has explored the users' (i) perceptions; (ii) experiences and, (iii) satisfaction level regarding the quality of HCG in a public hospital in Malaysia. The finding of this study reveals that:

(i) More than half of the respondents $(54.4 \%, n=25)$ reported a comfortable sensation with the outside air temperature of the HCG while sitting in the HCG. Measurement of air temperature outside the hospital and inside the HCG revealed that the average air temperature inside the courtyard is lower by $2.0^{\circ} \mathrm{C}$. The temperature recorded at $1 \mathrm{pm}$ on 10 th March 2018 revealed that the air temperature was $27.3^{\circ} \mathrm{C}$ in the $\mathrm{HCG}$ and $31.4^{\circ} \mathrm{C}$ outside the hospital with a significant temperature difference of $4.1^{\circ} \mathrm{C}$. Thus, this finding shows that courtyard provides a cooler and comfortable environment which is inviting to users (Mat Idris, Sibley and Hadjri, 2018).

(ii) The vast majority of the respondents agreed that as a result of being in the courtyard, they felt more relaxed and less stressed $(93.5 \%, n=43)$, more refreshed and rejuvenated $(87.0 \%, n=40)$, felt pleased, positive and better $(84.8 \%, n=39)$, felt calmer and able to think positively $(84.8 \%, n=39)$, comfortable $(84.8 \%, n=39)$, and safe $(82.6 \%, n=38)$. 
(iii) More than $80 \%$ of the respondents surveyed in the $\mathrm{H} 1$ hospital reported that they were satisfied with the design and planning of the HCG. This includes accessibility for wheelchair users $(86.9 \%, n=40)$, accessibility from main lobby to HCG $(82.6 \%, n=38)$, accessibility to different departments $(95.7 \%, n=44)$, accessibility to the HCG $(91.3 \%, n=42)$, visibility of the HCG from the adjacent space $(95.7 \%$, $n=44)$ and wayfinding to the HCG $(93.5 \%, n=43)$. Nevertheless, nearly half of the respondents were dissatisfied with the landscape elements $(47.8 \%, n=22)$ and the colour of the wall around the HCG $(41.3 \%(n=19)$.

Understanding how the physical environment including the design and planning, landscape elements, and microclimatic conditions influenced how users perceived and experienced the space as well as their expressed levels of satisfaction provides an insight into what architects and landscape architects should take into consideration when designing future hospitals with a large courtyard garden in a tropical climate. As mentioned previously, the work presented in this paper is part of an ongoing PhD research focusing on three Malaysian hospitals with different courtyard configuration which would lead to more robust evidence regarding the performance of the HCGs types in Malaysia. The results will therefore provide more reliable and comprehensive key finding which will inform the design of hospital courtyard in tropical climates.

Further research should include the perspective of the non-users of the HCG in order to provide an understanding of any barriers that restrained them from using it. Another potential avenue of work that could provide further information would be from the perspective of those who might be classed as non-active users (i.e. those who use the HCG for viewing from the inside of the hospital building either from a ward or a balcony). It is hoped that the finding from this ongoing POE work will contribute to the establishment of systematic evaluations of users' feedback particularly for HCGs in the tropics. The practical implication of the study is that both designers and hospital providers could learn from its findings to improve the planning and design of the HCGs in future as well as retrofit the existing ones.

\section{Acknowledgements}

I would like to thank the Director General of Health Malaysia, Ministry of Health Malaysia (MOH) for giving approval to submit this article for publication. I am very grateful to the hospital manager of the hospital $(\mathrm{H} 1)$ for granting permission to conduct the study at their respective hospital. Thank you to my supervisors, Dr Magda Sibley and Prof. Karim Hadjri, for their full support and constructive feedbacks in the preparation and completion of this paper. This paper is part of the ongoing PHD study which is fully funded by the Ministry of Higher Education Malaysia and Science Islamic University of Malaysia (USIM). This study has no conflict of interest.

\section{References}

Ahmed, K. S. (2003). Comfort in urban spaces: defining the boundaries of outdoor thermal comfort for the tropical urban environments. Energy and Buildings, 35(1), 103110.

Ali, S. B., and Patnaik, S. (2018). Thermal comfort in urban open spaces: Objective assessment and subjective perception study in tropical city of Bhopal, India. Urban climate, 24, 954-967.

Almhafdy, A., Ibrahim, N., Ahmad, S.S. and Yahya, J. (2013). Analysis of the Courtyard Functions and its Design Variants in the Malaysian Hospitals. Procedia-Social and Behavioral Sciences, 105, 171-182.

Almhafdy, A., Ahmad, S. S., and Wan Salleh, W. M. (2014). Courtyard as a Microclimatic Modifier Experimental Study on Actual Site. Applied Mechanics \& Materials, (567).

Almhafdy, A., Ibrahim, N., Ahmad, S. S., and Yahya, J. (2015). Thermal performance analysis of courtyards in a hot humid climate using Computational Fluid Dynamics CFD method. Procedia-Social and Behavioral Sciences, 170, 474-483.

Bordass, B., \& Leaman, A. (2005). Making feedback and post-occupancy evaluation routine 1: A portfolio of feedback techniques. Building Research \& Information, 33(4), $347-352$.

Butterfield, A. (2014). Resilient places? The healthcare gardens and the Maggie's Centres (Doctoral dissertation, University of the Arts London and Falmouth University).

Cooper Marcus, C., and Sachs, A.N. (2014) Therapeutic Landscapes. An Evidence-Based Approach to Designing Healing Gardens and Restorative Outdoor Spaces. New York: John Wiley \& Sons

Cooper Marcus, C., and Barnes, M. (1995). Gardens in healthcare facilities: Uses, therapeutic benefits, and design recommendations. Concord, CA: Center for Health Design.

Cooper Marcus, C., and Francis, C. (1998). People Places: Design Guidelines for Urban Open Space, 2nd ed. John Wiley \& Sons, Inc., Toronto

Davis, B. E. (2011). Rooftop hospital gardens for physical therapy: A post-occupancy evaluation. HERD: Health Environments Research \& Design Journal, 4(3), 14-43.

De Abreu-Harbich, L. V., Labaki, L. C., and Matzarakis, A. (2015). Effect of tree planting design and tree species on human thermal comfort in the tropics. Landscape and Urban Planning, 138, 99-109.

Ghaffarianhoseini, A., Berardi, U., and Ghaffarianhoseini, A. (2015). Thermal performance characteristics of unshaded courtyards in hot and humid climates. Building and Environment, 87, 154-168.

Ghazali, R., \& Abbas, M. Y. (2012). Natural environment in paediatric wards: Status and implications. Procedia-Social and Behavioral Sciences, 68, 173-182. 
Hadjri, K., and Crozier, C. (2009). Post-occupancy evaluation: Purpose, benefits and barriers. Facilities, 27(1/2), 21-33.

Ibrahim, F., Harun, W. M. W., Samad, M. H. A., and Kamaruddin, W. N. W. S. W. (2015). The Physical Attributes of Healing Garden for a Century Old Healthcare Premises International Transaction Journal of Engineering, Management, \& Applied Sciences \& Technologies, 6(2), 47-59.

Kruger, E. L., and Drach, P. (2017). Identifying potential effects from anthropometric variables on outdoor thermal comfort. Building and Environment, 117, 230-237.

Kubota, T., Zakaria, M. A., Abe, S., \& Toe, D. H. C. (2017). Thermal functions of internal courtyards in traditional Chinese shophouses in the hot-humid climate of Malaysia. Building and Environment, 112, 115-131.

Makaremi, N., Salleh, E., Jaafar, M. Z., \& GhaffarianHoseini, A. (2012). Thermal comfort conditions of shaded outdoor spaces in hot and humid climate of Malaysia. Building and environment, 48, 7-14.

Mastor, S. H., and Ibrahim, N. (2010). Post occupancy evaluation practices: a procedural model for a successful feedback. In Proceedings of the CIB 2010 World Congress, Salford Quays, United Kingdom (pp. 10-13).

Mat Idris, M., Sibley, M., and Hadjir, K. (2018). Investigating Space Use Patterns in a Malaysian Hospital Courtyard Garden: Lessons from real-time observation of patients, staff and visitors. Environment-Behaviour Proceedings Journal, 3(8), 32-45.

McIntyre, D.A. (1980) Indoor climate. Applied Science Publishers, London

Mohd Nawawi, N. (2011) Brief insights on the Post Occupancy Evaluation (POE) of Malaysian public healthcare facilities. In: Architectural Design Practice and Projects. IIUM Press, Kuala Lumpur, 49-60.

Naderi, J. R., \& Shin, W. H. (2008). Humane design for hospital landscapes: A case study in landscape architecture of a healing garden for nurses. HERD: Health Environments Research \& Design Journal, 2(1), 82-119.

Nawawi, A. H., \& Khalil, N. (2008). Post-occupancy evaluation correlated with building occupants' satisfaction: An approach to performance evaluation of government and public buildings. Journal of Building Appraisal, 4(2), 59-69.

Nikolopoulou, M., \& Lykoudis, S. (2006). Thermal comfort in outdoor urban spaces: analysis across different European countries. Building and environment, 41(11), 14551470

Pantavou, K., Theoharatos, G., Santamouris, M., \& Asimakopoulos, D. (2013). Outdoor thermal sensation of pedestrians in a Mediterranean climate and a comparison with UTCI. Building and Environment, 66, 82-95.

Pasha, S. (2013). Barriers to garden visitation in children's hospitals. HERD: Health Environments Research \& Design Journal, 6(4), 76-96.

Pasha, S., \& Shepley, M. M. (2013). Research note: Physical activity in pediatric healing gardens. Landscape and Urban Planning, 118, 53-58.

Preiser, W. F. E. (1995). Post-occupancy evaluation: How to make buildings work better. Facilities, 13(11), 19-28.

Sachs, N.A. (1999). The therapeutic value of outdoor space in psychiatric healthcare facilities. University of California, Berkeley.

Said, I., Salleh, S. Z., Bakar, M. S. A., \& Mohamad, I. (2005). Caregivers' Evaluation on Hospitalized Children' s Preferences Concerning Garden and Ward. Journal of Asian Architecture and Building Engineering, 4(2), 331-338.

Sharmin, T., Steemers, K., \& Matzarakis, A. (2015). Analysis of microclimatic diversity and outdoor thermal comfort perceptions in the tropical megacity Dhaka, Bangladesh. Building and Environment, 94, 734-750.

Sharmin, T., \& Steemers, K. (2018). Effects of microclimate and human parameters on outdoor thermal sensation in the high-density tropical context of Dhaka. International journal of biometeorology, 1-17.

Sherman, S. A., Varni, J. W. Ulrich, R. S. \& Malcarne, V. L. (2005). 'Post-occupancy evaluation of healing gardens in a paediatric cancer centre', Landscape and Urban Planning, 73(2-3), 167-183.

Shukor, S. F. A. (2012). Restorative Green Outdoor Environment at Acute Care Hospitals. Case Studies in Denmark. Forest \& Landscape Research, (57-2012).

Spagnolo, J., \& De Dear, R. (2003). A field study of thermal comfort in outdoor and semi-outdoor environments in subtropical Sydney Australia. Building and environment, $38(5), 721-738$.

Toone, T. L. (2008). Effects of Healing Garden Use on Stress Experienced by Parents of Patients in a Pediatric Hospital (Master dissertation, Texas A \& M University).

Whitehouse, S., Varni, J. W., Seid, M., Cooper-Marcus, C., Ensberg, M. J., Jacobs, J. R. \& Mehlenbeck, R. S. (2001). 'Evaluating a Children's Hospital Garden Environment: Utilization and Consumer Satisfaction', Journal of Environmental Psychology, 21(3), 301-314.

Yang, W., Wong, N. H., \& Jusuf, S. K. (2013). Thermal comfort in outdoor urban spaces in Singapore. Building and Environment, 59, 426-435. 